\title{
Ani Yağışlar ve Su Baskını Riski Altındaki Tarihi Yapılar İstanbul Tarihi Yarımada: Ahi Çelebi Camisi
}

\author{
${ }^{* 1}$ İlke Ciritci ve ${ }^{2}$ Gül Yücel \\ ${ }^{1}$ Uygulamalı Bilimler Yüksekokulu, Restorasyon ve Konservasyon Bölümü İstanbul Gelişim Üniversitesi, Türkiye \\ ${ }^{2}$ Mühendislik Mimarlık Fakültesi, Mimarlık Bölümü İstanbul Gelişim Üniversitesi, Türkiye
}

\section{Özet}

\begin{abstract}
Son yıllarda artan sağanak yağışlar, özellikle kentlerde ani su baskınlarına neden olmaktadır. Sağanak yağışın ardından yaşanan ani su baskınları sonucu önemli derecede işlev kaybı ve ekonomik zararla karşılaşılmaktadır. İstanbul'da topoğrafik olarak ani yağışlarda su altında kalma riski olan yerler özellikle dere yataklarıdır. Ancak tarihi yapılar kentteki değişim ve yol kotlarındaki düzenlemelere bağlı olarak kaldırım kotunun altında kalmaktadır. Çevresine göre daha alt kotta kalan tarihi yapılar, yağışlar sonucu ani su baskınlarına karşı risk altındadır. 17 Ağustos 2019'da yaşanan sağanak yağış, İstanbul tarihi kent merkezinde birçok yerde su baskınıyla sonuçlanmış, Küçük Ayasofya ve restorasyon sürecindeki Ahi Çelebi Camii sular altında kalmıştır. Çalışmada İstanbul Tarihi Yarımada'da ani yağışta su baskını riski yüksek tarihi yapılar değerlendirilmiştir. Bu kapsamda Haliç kıyısında konumlu Ahi Çelebi Camii ayrıntılı incelenmiştir. İncelemede konum, çevre topografya ile ilişkisi, ani su baskınlarına karşı alınmış önlemler ve daha önce bu türden risklerle karşılaşıp karşılaşmadığı araştırılmıştır. Çalışma verilerini arşiv bilgileri ve yerinde gözlem verileri oluşturmaktadır. İstanbul'da çoğu camii olmak üzere birçok tarihi yapının özgün kotu, çevresindeki yol kotundan daha aşağıdadır. Ani yağışlar sonucu gelişebilecek su baskınları için risk analizlerinin yapılarak, başta tarihi yapılar olmak üzere risk azaltıcı önlemler geliştirilmesine ihtiyaç duyulmaktadir.
\end{abstract}

Anahtar Kelimeler: Meteorolojik afet, su baskını, İstanbul tarihi yarımada, tarihi yapı, Ahi Çelebi Cami

\section{Giriş}

Afetler başta can kaybı ve yaralanma olmak üzere, fiziksel, sosyal ve ekonomik kayıplara neden olmaktadır. Sel, depremle birlikte en yaygın doğa kaynaklı afetlerin başında gelmektedir. Dünyanın birçok bölgesinde, birçok yerleşimde sel beraberinde yıkım getirmektedir. Küresel iklim değişikliği beraberinde, etkileri ve sonuçları daha da kötüye doğru gitmektedir. Federal Acil Durum Yönetimi Ajansı (FEMA) kentsel taşkını;

“...geçirimsiz yüzeylerin artış gösterdiği, özellikle yüksek yoğunlukta nüfus barındiran yerleşimlerde, drenaj kapasitesinin üzerinde gelişen sağanak yağmur nedeniyle binaların su altında kalmast..."

olarak tanımlamaktadır [1]. Fosil yakıt kullanımı, enerji tüketimi, hızlı nüfus artışına bağlı olarak sanayileşme, orman yangınları ve insan etkileri sonucunda atmosfere salınan gazların sera etkisi

\footnotetext{
${ }^{*}$ Corresponding author: Address: School of Applied Sciences, Department of Restoration and Conservation Gelisim University, 34310, Istanbul TURKEY. E-mail address: iciritci@ gelisim.edu.tr, Phone: +902124227000
} 
yaratmasıyla oluşan küresel iklim değişikliği ve buna bağlı olarak gerçekleşen ani meteorolojik değişimler, doğa kaynaklı afetlerin şiddetini ve sayısını da arttırmaktadır. İklim araştırmacıları son 30 yılda dünya genelindeki yağmur miktarında yüzde 20'lik bir artış olduğunu tespit etmiştir. Küresel klim değişikliği ile birlikte afetlerin yıkıcı etkisi de gün geçtikçe artmaktadır. Ani seller (Flash Floods) altı saat içinde oluşabilir. Ani seller, çöller dâhil dünyanın her yerinde görülebilmektedir [2]. Bilim insanlarına göre sel felaketinin meydana geldiği bölgelerde, halkın yaklaşık yüzde 10'u hem can hem de mal kayıpları açısından risk altındadır. Önlem alınmadığı takdirde bu oranın artmasının kaçınılmaz olduğu ortak görüştür.

İklim değişikliği, bu yüzyıl boyunca devam etmesi beklenen bir eğilim olan en güçlü firtınalarının sıklığını arttırmaktadır. IPCC'nin (Hükümetler Arası İklim Değişikliği Paneli) özel raporunda belirtildiği gibi, iklim değişikliğinin, yağış ve kar erimesi gibi su baskınlarına neden olan su ile ilgili değişkenlerin "tespit edilebilir bir şekilde etkilediği" açık bir şekilde ortaya konmuştur. Raporda ayrıca iklim değişikliğinden etkilenmeyecek ülke ve bölge olmadığı belirtilmektedir. IPCC'nin senaryosuna göre Türkiye'de yıllık ortalama sıcaklığının 2,5-4 arasında artacağı tespit edilmiştir. Gökçe Ö., vd, [3].'nin hazırladıkları rapora göre Türkiye için su baskınları afet olay sayısının afet türlerine göre dağılımına göre $\% 14$ ile heyelan ve depremden sonra üçüncü sırada yer almakta, toplam afetzede sayısının afet türlerine göre dağılımına göre ise $\% 8$ ile heyelan ve depremden sonra yine 3.sirada yer almaktadir.

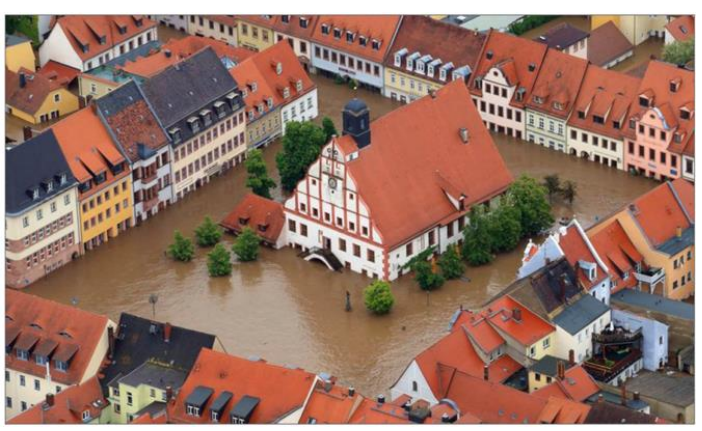

a)

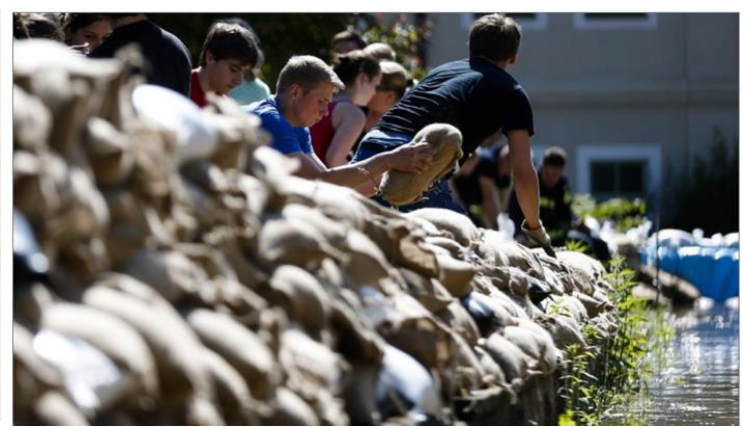

b)

Şekil 1. a) Almanya, Grimma şehir merkezi, ani sel baskını 3 Haziran 2013

b) Aynı sel baskınında Elbe Nehrinin de taşması ile Almanya Dresden'de gençler kum torbalarıyla önlem almaya çalışıyor, 5 Haziran 2013 [4]

Macaristan, 2013 yılında tarihinin en büyük sel faleketiyle karşı karşıya kalmış ve su seviyesi beklentilerinde üzerine rekor seviyeye çıkmıştır. Su seviyesinin yükselmesiyle birçok yerleşimde evler sular altında kalmıştır. Taşan Tuna Nehri kıyısındaki tüm yollar trafiğe kapatılmış bölgedeki yerleşim yerleri tahliye edilmiştir [5]. Aynı sel baskınında Almanya ve Çek Cumhuriyeti'nde yaşayan da benzer problemlerle karşılaşmış ve evlerini tahliye etmek zorunda kalmışlardır (Şekil 1).

Türkiye'de Edirne'den geçen Meriç ve Tunca Nehri ve bu nehirlere bağl1 pek çok dere de, benzer ani sağanak yağışların ardından taşıp çevresinde yeralan yerleşimler için tehdit haline gelebilmektedir (Şekil 2). Diğer taraftan başta İstanbul olmak üzere birçok kıyı kentinde ani su baskınlarıyla karşı karşıya kalınmaktadır. İstanbul'un topoğrafik olarak ani yağışlarda su altında kalma riski olan yerleri özellikle dere yataklarının olduğu alanlardır. Ancak tarihi yapılar zaman içinde yol kotlarındaki düzenlemelere bağlı olarak kaldırım kotunun altında kalabilmektedir. 
Çevresine göre daha alt kotta kalan tarihi yapılar yağışlar sonucu ani su baskınlarına karşı zayıf durumdadir.
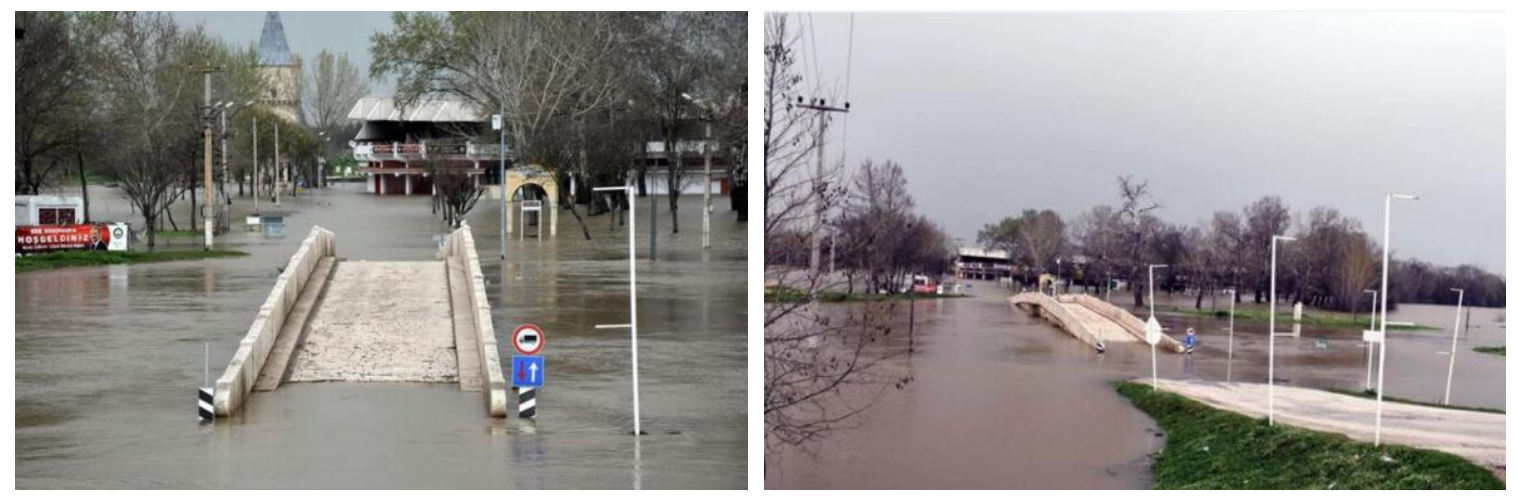

Şekil 2. Edirne'de 26 Mart 2018 tarihli ani sağanak sonrası taşan nehir ve sular altında kalan tarihi köprü [6]

17 Ağustos 2019'da yaşanan sağanak yağış İstanbul merkezinde birçok yerde su baskınına yol açmıştır. Bu yapılardan biri de Ahi Çelebi Camii'dir (Şekil 3). Ahi Çelebi Camii'nin Haliç kıyısında yer alması, zemin yapısı ve son dönemde artan ani yağışlarla birlikte su baskınları yaşamakta ve zarar görmesine neden olmaktadır. Tarihi yapılar için su baskınları özellikle su ve nemin getirdiği sorunlarla birlikte yapısal açıdan sorun oluşturabilmektedir. Ahi Çelebi Camii ve benzeri tarihi yapılar için su baskını riskinin değerlendirilmesi ve risk azaltıcı önlemler alınması önemlidir.
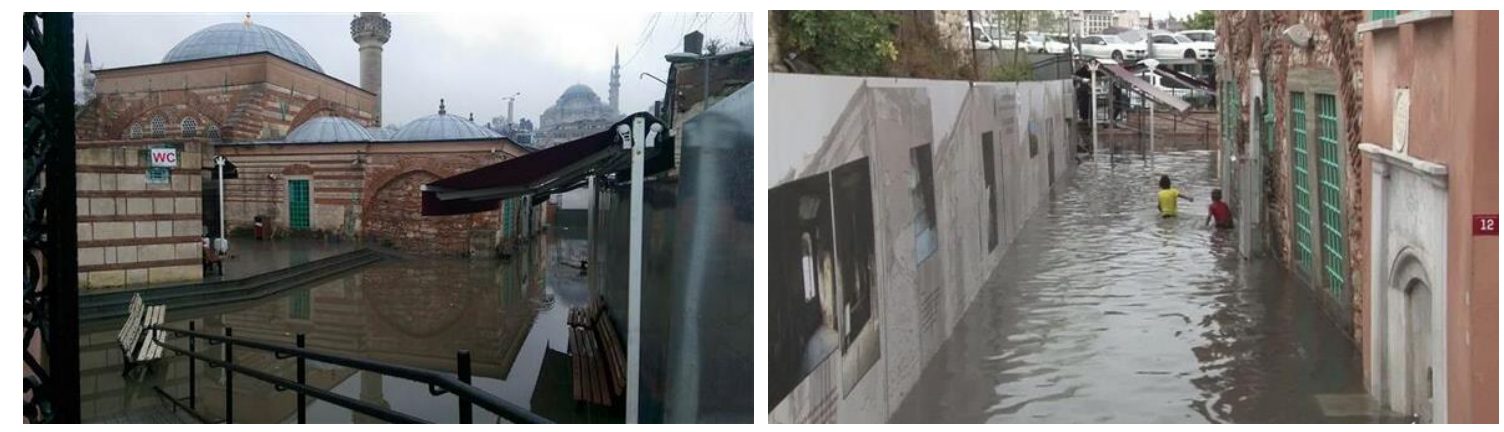

Şekil 3. Ahi Çelebi Camii 2018 ve 2019 ani yağı̧s sonrası su baskını [7], [8]

\section{Materyal ve yöntem}

Çalışmada İstanbul Tarihi Yarımada'da bulunan tarihi yapılar incelenmiştir. İncelemede çevre yol kotunun altında kalan ve birçok su baskını yaşamış tarihi yapılar dikkate alınmıştır. Bunların büyük bir kısmını tarihi camiler oluşturmaktadır. Çalışma kapsamında Eminönü semtinde ve Haliç kıyısında yeralan Ahi Çelebi Camii ayrıntılı ele alınmıştır.

İnceleme verilerini hâlihazır haritalar, arşiv bilgileri ve yerinde gözlem yoluyla elde edilen bilgiler ve saha görüşmeleri oluşturmaktadır. Değerlendirmede tarihi yapının afet geçmişi, bulunduğu özgün kot ve çevre kotları, topografyanın durumu, yakın çevrede su baskını 
oluşturacak potansiyel kaynaklar dikkate alınmıştır. Yerinde gözlem ve inceleme Eylül 2019 tarihinde gerçekleştirilmiştir.

\section{3.İstanbul Tarihi Yarımada ve tarihi yapılarda su baskını riskleri}

İstanbul'da pek çok tarihi eserin bir arada bulunduğu ve bütüncül koruma kararları olan bölgesi, Tarihi Yarımadadır (Şekil 4). Üç büyük imparatorluğa başkentlik yapmış, dünyayı 2 bin700 y1l yöneten bir şehir olan İstanbul, 8bin 500 yıllık yerleşim tarihine sahiptir. Açığa çıkarılan eserlerin çoğu medeniyetlere merkez olmuş, günümüzde Tarihi Yarımada olarak adlandırılan bölgededir.

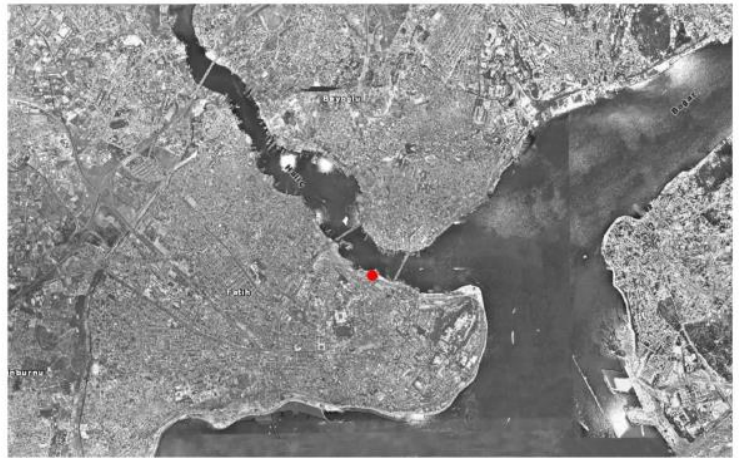

a)

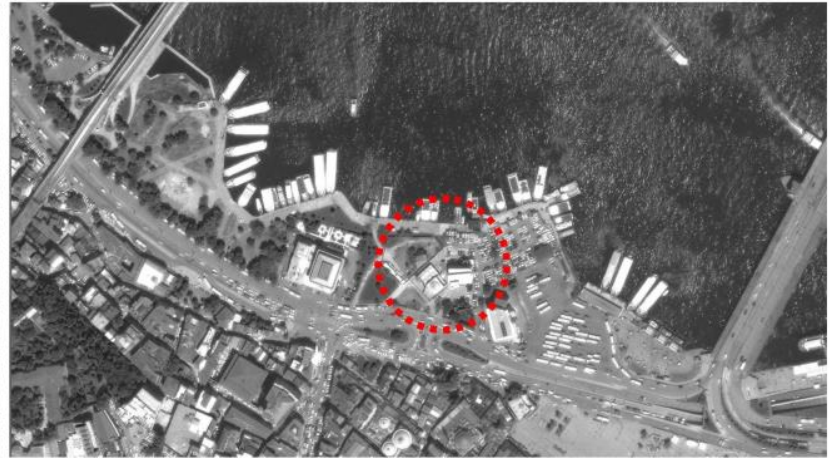

b)

Şekil 4. a) İstanbul Tarihi Yarımada haritası, b) Ahi Çelebi Camii konumu [9]

İstanbul Tarihi Yarımada; geçmişten günümüze tarih ve kültürün birleştiği, bütünleştiği katmanlaşmış yapısıyla farklı kesitleri bir arada barındıran yapıdadır. Bizans'tan günümüze farklı teknik, ölçek, işlevle bütünleşmiş yapılardan bir kısmı Tarihi Yarımada'nın bugünkü koşullarında özgün yapısını korumakta sorun yaşayabilmektedir. Tarihi yapıların özgün zemin kotu, çevresiyle bütünleşmede bu anlamda en çok etkilenen konulardan biridir. Roma İmparatoru I. Konstantinus'un 4.yüzyılda diktiği kabul edilen 'Milyon Taşı' günümüz zemin kotuyla ilişkisinde yükselmiş olan zemini görmek için iyi bir örnektir.

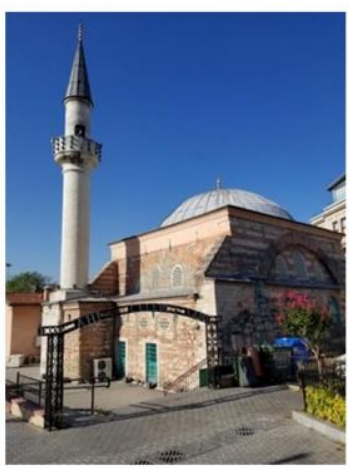

a)

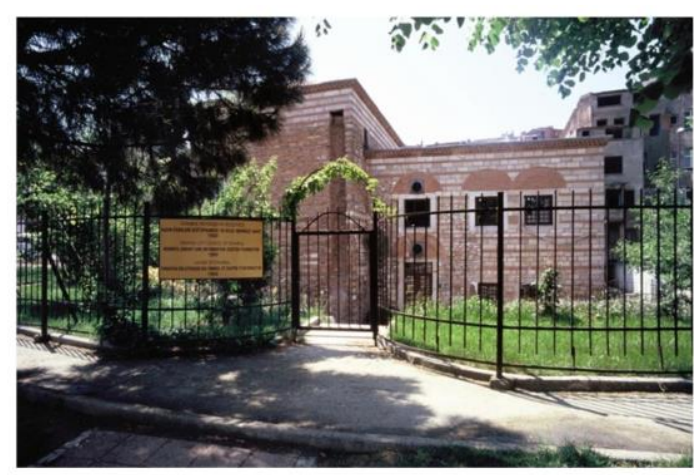

b)

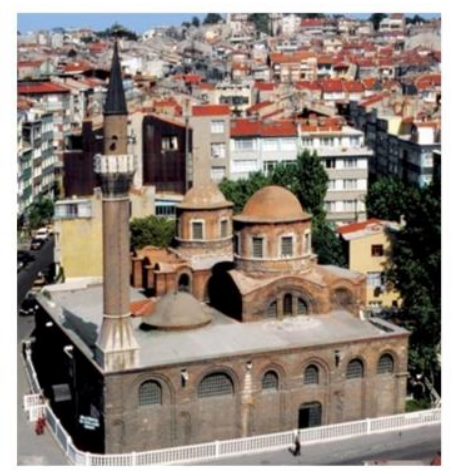

c)

Şekil 5. a. Ahi Çelebi Cami [10] b. Kadın Eserleri Kütüphanesi [11] c. Molla Fenari Camii (907) (Constantinos Lips Manastırı ) Cami [12] 
İstanbul'da farklı dönemlerde yeniden ele alınan ulaşım ağındaki değişiklik ve düzenlemeler nedeniyle birçok yapı zemin seviyesinin altında kalabilmektedir. Özellikle tarihi yapıların çevreyle bağlantısında da yeni duruma neden olmaktadır. Çevresindeki yol kotuna göre çukurda kalmış tarihi yapılara Küçük Ayasofya Camii- SS. Sergius ve Bacchus Kilisesi (MS 527-536), Ahi Çelebi Camii (MS 500) [17], Kadın Eserleri Kütüphanesi [18], Sultan Selim Medresesi [19], Pertevniyal Valide Sultan Camii (1867-1871), Azapkapı Sokullu Mehmet Paşa Camii (1577-78), Molla Fenari Camii (907) (Constantinos Lips Manastırı) örnek verilebilir (Şekil 5, 6, 7). Bütün benzeri koşullardaki tarihi yapılar için su baskın risk analizlerinin yapılması ve gerekli önlemlerin alınması, yapıların gelecek kuşaklara aktarımında önemlidir.

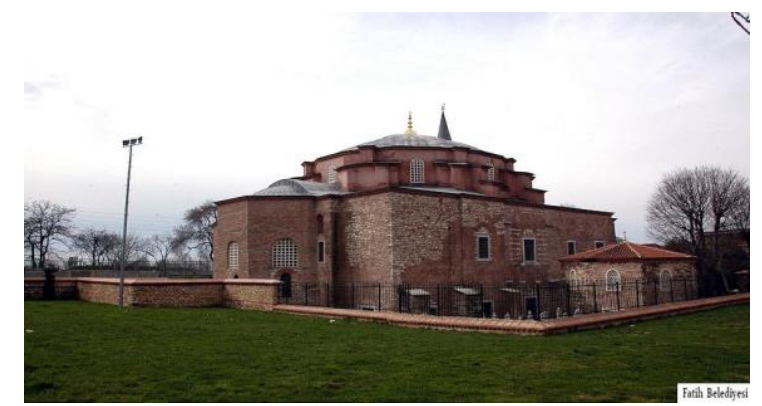

a)

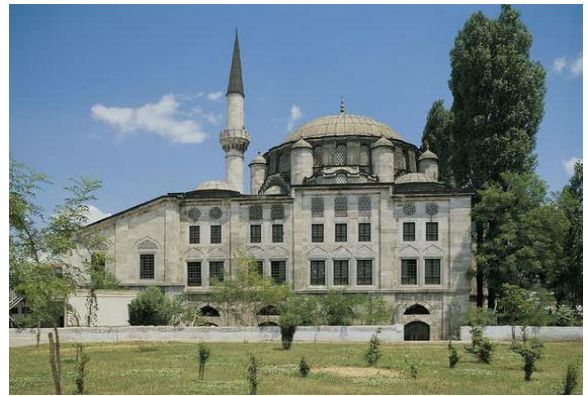

b)

Şekil 6. a. Küçük Ayasofya Camii- SS. Sergius ve Bacchus Kilisesi (MS 527-536) [13] b. Azapkap1 Sokullu Mehmet Paşa Camii (1577-78) [14]

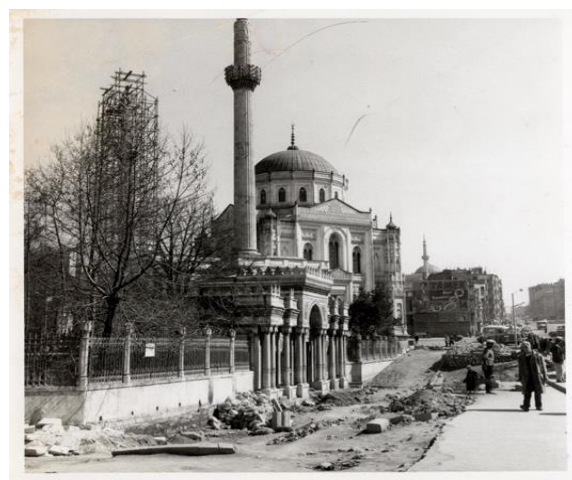

a)

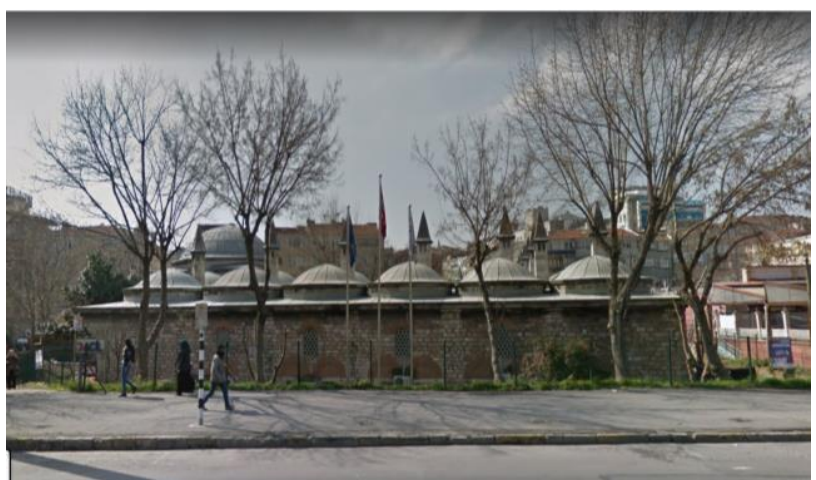

b)

Şekil 7. a. Pertevniyal Valide Camii [15] b. Sultan Selim Medresesi veya Halıcılar Köşkü Medresesi veya Sultan Selim Kadim Medresesi (M.1548-49 C. Baltac1) [16]

\section{Ahi Çelebi Camii}

Ahi Çelebi Cami, Tarihi Yarımada Eminönü'nde Haliç sahil şeridinde yer almaktadır (Şekil 4, 5, 8). Yapım dönemi 1500’lü yıllara tarihlenmektedir. Yapının banisi Ahi Çelebi Tabib Kemal Osmanlı İmparatorluğu'nun en parlak dönemlerinde yaşamış önemli doktorlarındandır [20]. Cami Piri Reis'in İstanbul planında ve Matrakçı Nasuh'un İstanbul minyatürlerinde de görülmektedir [21]. Çeşmesi, Şadırvanı, mahkemesi, hapishanesi, türbeleri, kapalıçarşısı, deniz suru ve kapısı, iskelesi, iskele meydanı ve Haliç üzerinde Çardak Kahvesi ile zaman içinde özel bir külliye oluşturmuştur [22]. Ahi Çelebi Cami bugün Zindankapı mahallesindeki Zindankap1 Caddesi, Balık Pazarı Değirmen Sokağı ve Yoğurtçu Hüseyin Sokağı arasında kalan adacığı doldurmaktadır. Cami kapısı Balık Pazarı Değirmen sokağına açılmaktadır. 
Cami yaklaşık 24.54x16.90 m taban alanlı [22] ve Haliç yönünde genişleyen bahçe içindedir. Cami simetrik bir planlıdır. Kâgir beden duvarları üzerine oturan kurşun kaplı $11 \mathrm{~m}$ çapında tek kubbesi bulunmaktadır. Binanın kare şeklindeki kubbe kasnağı demirle çevrilidir. Son cemaat yeri $4 \mathrm{~m}$ çapında altı adet dairesel kubbe ile örtülüdür. Taşıyıcı duvarların kalınlıkları 100-150 cm arasında değişmektedir. Cami beden duvarlarında çok farklı tip ve boyutlarda taşların kullanıldığı görülmektedir. Genellikle ana duvarlarda beyaz kireçtaşı/ küfeki taşı, çerçevelerde, alt ve üst kapaklarda pencere ve kapılarda ateş taşı kullanılmıştır [22]. Cami'nin yanlara doğru ikişer payandanın da onarımlar sırasında eklendiği anlaşılmaktadır.
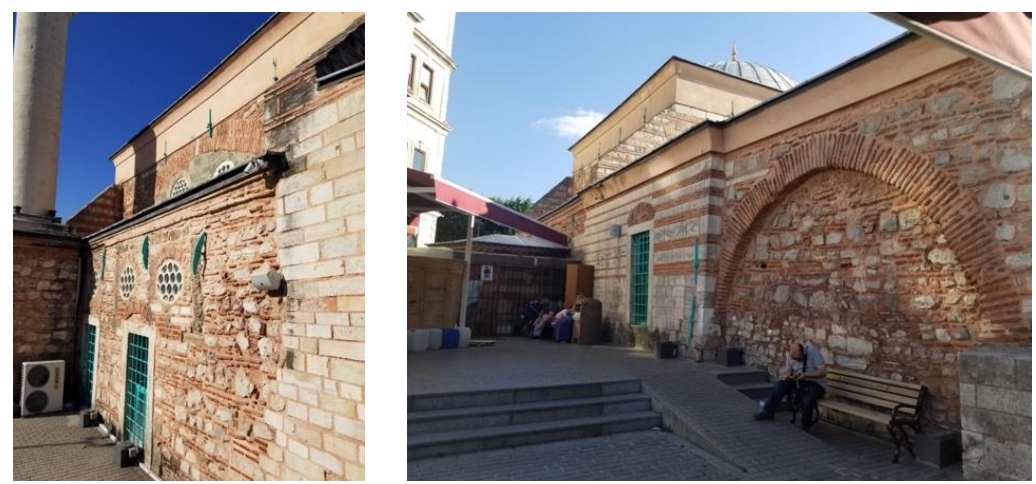

Şekil 8. Ahi Çelebi Cami genel görünüm (Fotoğraf: İ. Ciritci, 2019)

\subsection{Geçirdiği Afetler ve Bakım Onarım Çalışmaları}

Ahi Çelebi Camii yapımından günümüze 500 yılı aşan süreçte geçirdiği afetler ve onarımlar, Tablo.1'de özetlenmiştir. Toptaç [23] 1510 yılında gerçekleşen depremden hasar alan yapının ilk olarak Mimar Hayrettin tarafından bu tarihte onarıldığından bahsetmektedir. Cami, 1653 yangınından sonra Mimar Sinan tarafından onarıldığı için Tezkiret'ül Enbiye'de onun eseri olarak geçmektedir [24]. Mimar Sinan'ın onarımının sonrasına tarihlenen 1585 yılındaki gravürde caminin tek kubbeli ana mekândan ve üç kubbeli arka cemaat alanından oluştuğu görülmektedir. Eyüpgiller [25] Sinan tarafından yapılan onarımda eski yapının sadece ana duvarlarının kullanıldığı, orta mekânın kubbe ile örtülmüş olduğu ve alanın her iki tarafina da birer destek ayak ekleyerek tonozlarla kapatıldığını belirtmektedir. Diğer taraftan 2004 yılında Kutgün Eyüpgiller'in danışmanlığında hazırlanan restitüsyon çalışmalarında caminin ilk planının ahşap kırma çatılı, yığma duvarlı ve dikdörtgen planlı ana mekandan ve üç bölümden oluşan kemerli bir arka toplama alanından oluştuğu ve batı duvarına bitişik dış girişi olan bir minaresinin olduğu düşünülmektedir [26].

Ahi Çelebi Camisi'nin 1652 yangınında tamamen yıkıldığı söylenmiş olsa da, Cezar'a göre [27] binadaki 17. yüzyıla ait izler bu görüşü doğrulamamaktadır. Yapının bu yangından etkilendiği düşünülmekle birlikte plan şemasında büyük değişiklik ve ek yapılmamıştır. 18.yüzyılda ana kubbenin onarıldığ 1 , doğu ve batı cephelerinin payandalarla desteklendiği ve camiye ikinci bir arka cemaat alanı eklendiği düşünülmektedir [25]. 19. Yüzyılda Caminin 1818 ve 1852 yıllarında yakın çevrede çıkan yangınlardan zarar görmüş olabileceği, giriş cephesinin batısında yer alan 1864 tarihli çeşmenin, bu yangınlardan sonra yapılan onarımlarda binaya bağlanmış olabileceği ve minarenin de bu süreçte yeniden inşa edildiği düşünülmektedir [27]. Haliç Sahili yönünden zeminine su alan Cami, 1894'teki depreminde büyük zarar görmüştür. Deprem sonrası ana duvarları demir kenet ile desteklenmiş, pencereler doldurularak yükseltilmiş, ana mekânın doğu 
ve batı cephelerinde oval pencereler açılmış, yan hacimlere kemerler eklenmiş ve kubbe kasnağı demirle desteklenmiştir [23]. Cami, 1980'lerde Haliç'te yapılan peyzaj çalışmaları kapsamında yapılan yeni Galata Köprüsü inşaatı ve kazı çalışmalarından etkilenmiş; inşaat çalışmaları sırasında tehlikeye girerken meydana gelen sarsıntılar caminin duvarlarında çatlakların ortaya çıkmasına neden olmuştur. Zaman içerisinde birbirine bağlanan kemerlerde bükülme ve burkulmalar ortaya çıkmış, cami Haliç'e doğru kaymaya başlamış, temeli zarar görmüş ve ibadete kapatılmıştır [22].

Tablo 1. Ahi Çelebi Cami ve karşılaştığı afetler ve alınan önlemler

\begin{tabular}{|c|c|c|c|}
\hline & Tarih & Olay & Hasar ve müdahale \\
\hline $\mathbf{1}$ & 1510 & Deprem & Mimar Hayrettin tarafindan onarılmıștır. \\
\hline 2 & 1539 & Zindankapı Yangını & Mimar Sinan tarafindan onarılmıştır. \\
\hline 3 & 1653 & Oduncu Kapıs1 Yanginı & Tamamen yanar. \\
\hline 4 & 1688 & Yangın & $\begin{array}{c}\text { Ahi Çelebi Cami ve mahkemesi ile abacı, mumcu, yemişçi, tuz, } \\
\text { soğan, sarımsak, arpa, yağ ve bal satan birçok esnafın dükkânları } \\
\text { yandı [28]. }\end{array}$ \\
\hline 5 & 1894 & $\begin{array}{l}\text { Deprem ve ardından } \\
\text { zemin sorunu nedeniyle } \\
\text { su baskını }\end{array}$ & $\begin{array}{l}\text { Cami deprem nedeniyle yere batarak bel seviyesine kadar su dolar. } \\
\text { Yıllarca kullanım dışı kalır. }\end{array}$ \\
\hline 6 & 1918 & & Su basan yerler toprakla doldurulur ve strüktürel güçlendirme yapılır. \\
\hline 7 & 1980 & & \\
\hline 8 & 1990-1997 & Onarım & $\begin{array}{c}\text { Vakıflar Genel Müdürlüğü tarafından onarım yapılmıştır. Sivalar } \\
\text { raspa edilmiş, kubbe kurşunları sökülmüş, etrafındaki niteliksiz } \\
\text { yapılar kaldırılarak cami ortaya çıkarılmıştır. Zeminden kaynaklanan } \\
\text { sorunlar nedeniyle yapı̈ı strüktürel çatlaklar oluştuğu Haliç’e doğru } \\
\text { çöktüğü tespit edilmiştir. Yapının dış duvarları ile ana kubbesi altında } \\
\text { kalan temellerine enjeksiyon yapılmıștır. }\end{array}$ \\
\hline 9 & $2000-2007$ & Kapsamlı onarım & $\begin{array}{l}\text { Vakıflar Genel Müdürlüğü denetiminde yapılan onarımda; Çevre } \\
\text { drenajı, zemin iyileştirme kapsamında fore kazık uygulaması, Cami } \\
\text { çevresinde zemin kotu değişmesi; minarenin yeniden yapımı } \\
\text { uygulanmaştır (Vakıflar İstanbul 1. Bölge Müdürlüğü Arşivi) [29]. }\end{array}$ \\
\hline 10 & 10.Ara.10 & Su baskını & Sağanak yağış ve Su baskını [30] \\
\hline 11 & 18.Tem.17 & Su baskını & {$[31],[32]$} \\
\hline 12 & 28.Şub.18 & Su baskını & $\begin{array}{l}\text { Sağanak yağı̧s sonrası su baskını ve kullanım dışı kalması } \\
{[33],[34]}\end{array}$ \\
\hline 13 & 17.Ağu.19 & Su baskinı & 17 Ağustos 2019 'da ani sağanak yağıș sonrası su baskını. [35] \\
\hline
\end{tabular}

1990 yılında kubbede, duvarlarda ve taşıyıcı elemanlarda oluşan çatlakları takiben Cami zemininde iyileştirme çalışmaları başlatılmış ancak tamamlanamamıştır [23]. 1993 yılında yapılan tespitler neticesinde 1995 yılında Cami'nin projeleri ve teknik raporları hazırlanmış ve zemin güçlendirme çalışmaları yeniden başlatılmıştır. Bu çalışma 1997 yılının sonunda ilk aşamadan sonra durdurulmuş olmakla beraber 1999 'da Marmara depremi nedeniyle yapısal sorunların artması neticesinde, caminin acil olarak onarılması gündeme gelmiştir. Zemin güçlendirme çalışmaları 2000 yılında da sürdürülmüş; taban seviyesindeki deniz suyu boşaltılmıştır [26]. Caminin restorasyonu 2004 yılında onaylanmış projesine göre 2006 yılının sonunda tamamlanmıştır. 
Ahi Çelebi Camii son 10 yıldır sağanak yağış sonrası su baskınları ile karşılaşmaktadır. Cami, üzerine kurulduğu dolgu zemin, yeri ve konumundan ötürü sık sık sular altında kalmaktadır. Bu nedenle taşıyıcı sistemi çökmüş ve desteklenmesi gerekmiştir (Tablo 1). Ahunbay’a [36] göre,

“...1894 yılındaki deprem sonrası yapılan sağlamlaştırma müdahalelerinde demir çekme çubuklarl, kulıçlar ve od taşı kullanılmıştır. Son cemaat yerinde ve harimdeki taşlyıcıların kesitleri, etraflarına od taşından gömlek örülerek büyütülmüştür. Od taşı sonradan kapatılan cemaat yeri revak cephesindeki pencere sövelerinde de kullanılmıştır. 1999 depremi sonrasında yapılan onarımla, caminin güneybatı cephesinde kubbe kemerleri altında bulunan od taşı örgü açı̆̆a çıkmıştır."

2006 yılında Ahi Çelebi Cami ibadete açılmadan önce yapılan son kapsamlı onarım çalışmasında yapılan işlemlerden bazıları; mikro kazıklarla güçlendirme, borularla deniz suyunun boşaltılması, tüm cephelerin temizlenmesi, yapısal çatlakların kuvvetlendirilmesi, kılcal çatlakların doldurulması, duvarlarda od/ateş taşının yenilenmesi, kubbenin çelik dairesel kemer-kenetlerle güçlendirilmesi ve böylece normal gerilmelerin \%60 oranında düşürülmesi, tonoz örtünün sökülüp yeniden yapılması, hasarlı kurşunun çıkarılması ve geleneksel yöntemlerle yeniden yapılması, payandaların onarımı, korozyon tespit edilen tüm demir bileşenlerinin değiştirilmesi, ekseni kayan minare gövdesinin orijinaline uygun malzeme ile onarılması şeklinde oldukça ayrıntılı ve çok yönlüdür [26].

\section{Bulgular ve Tartışma}

Ahi Çelebi Camii yapıldığı günden bugüne yangın, deprem, su baskını gibi birçok afetle karşı karşıya kalmıştır. Deprem etkileri ve zemin sorunları nedeniyle zemin iyileştirme yapılmış ve camide strüktürel önlemler alınmıştır. Haliç kıyısında olması zemin problemi yanında su baskını riskini de beraberinde getirmektedir. Çevre düzenlemeleri ve farklı tür tehlikelerin etkisinde kalması da camide hasara neden olmuştur. Tüm onarım çalışmalarında son teknolojiden faydanılmış ve restorasyon ilkeleri kapsamında her veri detaylı bir biçimde analiz edilip en doğru uygulama yöntemi seçilmiştir. Çevre drenajı olsa da cami zemini çevre kotlarına göre aşağıda olması nedeniyle su baskın riski taşımaktadır. Son yıllarda yaşanan sağanak yağış sonrası su baskınları, kent bütününde ve özellikle yol kotu altında kalan tarihi yapılar için önlemlerin alınmasını gerektirmektedir. Aynı zamanda tarihi yapıların bulundukları topoğrafyanın getirdiği koşullar yapı özerinde çalışmayı gerektirmektedir.

\section{Değerlendirme}

Tarihi yapılar işlevini sürdürmekle birlikte kurulduğu dönemdeki özgün çevre kotları değişmiş ve yapılara girişler çevreden daha düşük kottaki bahçesine merdivenle ulaşımı da beraberinde getirmiştir. Diğer yandan yağışların etkisi bu türden zemin seviyesinin altındaki yapılar için tehdit edici olmaktadır. Son yıllarda artış gösteren sağanak yağışlar ani su baskınlarına neden olabilmektedir. Özellikle deniz veya dere yataklarına yakınlık bu açıdan riski daha da artırmaktadir.

İstanbul için dere yatakları ve deniz kıyısı su baskın riskleri açısından önem taşımaktadır. Günümüzde yol kotu altında kalmış birçok tarihi yapı su baskınlarına karşı risk altındadır. Tarihi Yarımada başta olmak üzere ani sağanak yağışlara bağlı olası su baskın alanları belirlenmeli ve 
risk azaltıcı önlemler geliştirilmelidir. Yapılacak analizlerle riskli alanlar belirlenmelidir. Risk azaltma çalışmalarıyla birlikte tarihi yapılar için afete karşı dirençliliğin ön plana çıkarıldığ yapısal önlemler öncelikli düşünülmelidir.

\section{Kaynaklar}

[1] Weber Anna. What Is Urban Flooding? Natural Resouces Defense Council, NRDC. 15.01.2019. https://www.nrdc.org/experts/anna-weber/what-urban-flooding (15.09.2019 tarihinde erişilmiştir).

[2] Kadığlu, M. 2008, Sel, Heyelan ve Çı̆̆ için Risk Yönetimi, Afet Zararlarını Azaltmanın Temel İlkeleri, JICA Türkiye Ofisi Yayınları No:2 s 251-276, Ankara

[3] Gökçe O., Özden Ş., Demir A., 2008, Türkiye'de Afetlerin Mekansal ve İstatiksel Dağılımı Afet Bilgileri Envanteri, T.C. Bayındırlık ve İskan Bakanlığı Afet İşleri Genel Müdürlüğü, Afet Etüt ve Hasar Tespit Daire Başkanlığı, Ankara

[4] Flooding Across Central Europe, AP Photo/dpa, Jens Wolf. The Atlantic. 07062013. https://www.theatlantic.com/photo/2013/06/flooding-across-central-europe/100530/ (20.09.2019 tarihinde erişilmiştir).

[5] Euronews. Macaristan'da sel seferberliği, 09.06.2013. The Euronews. $09 \quad 062013$. https://tr.euronews.com/2013/06/09/macaristan-da-sel-seferberligi (20.09.2019 tarihinde erişilmiştir).

[6] Edirne'de sel alarmı, karayolu trafiğe kapandı. CNNTÜRK. $26 \quad 03 \quad 2018$. https://www.cnnturk.com/turkiye/edirnede-sel-alarmi-karayolu-trafige-kapandi?page=12 (20.09.2019 tarihinde erişilmiştir).

[7] Günal, Zeki. Ahi Çelebi Camii'nin bahçesini su bastı. Hürriyet Gazetesi. 28022018. http://www.hurriyet.com.tr/galeri-ahi-celebi-camiinin-bahcesini-su-basti-40756421?p=3 tarihinde erişilmiştir).

[8] Tarihi Ahi Çelebi Camii sular altında kaldı! 1708 2019. https://www.aksam.com.tr/guncel/tarihi-ahicelebi-camii-sular-altinda-kaldi/haber-998339 (20.09.2019 tarihinde erişilmiştir).

[9] İstanbul Şehir Haritas1. 10.09.2019. https://sehirharitasi.ibb.gov.tr/.

[10] Fotoğraf Galerisi . Kadın Eserleri Kütüphanesi ve Bilgi Merkezi Vakfi. http://kadineserleri.org/fotograf-galerisi/ (20.09.2019 tarihinde erişilmiştir).

[11] Fotoğraf Galerisi. Kadın Eserleri Kütüphanesi ve Bilgi Merkezi Vakfi. http://kadineserleri.org/fotograf-galerisi/ (20.09.2019 tarihinde erişilmiştir).

[12] Eyice, Semavi. FENÂRÎ ÎSÂ CAMİI. Türkiye Diyanet Vakfı İslam Ansiklopedisi. https://islamansiklopedisi.org.tr/fenari-isa-camii (15.09.2019 tarihinde erişilmiştir).

[13] Fotoğraflarla Tarih, Küçük Ayasofya Camii. Fatih Belediyesi. http://www.fatih.bel.tr/Gallery.aspx?GalleryID=1114 (20.09.2019 tarihinde erişilmiştir).

[14] Sokullu Mehmet Paşa Camii. Archnet. https://archnet.org/sites/2792 (20.09.2019 tarihinde erişilmiştir).

[15] Pertevniyal Valide Sultan Camii - The Pertevniyal Valide Sultan Mosque. SALT Araştırma. https://archives.saltresearch.org/handle/123456789/72095 (20.09.2019 tarihinde erişilmiştir).

[16] Sultan Selim Medresesi, Vatan Caddesi'nin Sokak görünümü. GoogleMap. https://www.google.com/maps/ (20.09.2019 tarihinde erişilmiştir).

[17] Ahi Çelebi Cami. İstanbul Kültür Mirası ve Ekonomi Mirası Envanteri 2010. 0110 2010.http://www.envanter.gov.tr/anit/index/detay/50151\%20son\%20eri\%C5\%9Fim\%2022.09.2019 (20.09.2019 tarihinde erişilmiştir).

[18] Kadın Eserleri Kütüphanesi ve Bilgi Merkezi Vakfi. Arkiv. http://www.arkiv.com.tr/proje/kadineserleri-kutuphanesi-ve-bilgi-merkezi-vakfi/8978 (20.09.2019 tarihinde erişilmiştir). 
[19] Sultan Selim Medresesi. Envanter, İstanbul Kültür Miras1 ve Kültür Ekonomisi Envanteri 2010. 0110 2010. http://www.envanter.gov.tr/anit/index/detay/47228 (20.09.2019 tarihinde erişilmiş̧tir).

[20] Evliya Çelebi'yi Seyyah Yapan Ahi Çelebi Camii. Şehri İstanbul Blog. http://sehristanbul.blogspot.com/2011/11/evliya-celebiyi-seyyah-yapan-ahi-celebi.html $\quad(20.09 .2019 \quad$ tarihinde erişilmiştir).

[21] Aslan D., 2017, Ahi Çelebi Evkaf Mahkemesi 6 Numaralı Defterinin Transkripsiyonu ve Değerlendirilmesi, T.C. Afyon Kocatepe Üniversitesi Sosyal Bilimler Enstitüsü Tarih Ana Bilim Dalında hazırlanan Yüksek Lisans Tezi, Afyon Karahisar.

[22] Sesigür H., Çelik O.C., Çı1ı F., 27-29 Eylül 2007, Ahi Çelebi Camisinin Onarımı ve Güçlendirilmesi, Tarihi Eserlerin Güçlendirilmesi ve Geleceğe Güvenle Devredilmesi Sempozyumu-I, Kongre Sempozyum Bildiriler Kitab1, s 231-241, Ankara

[23] Topkaç, S., 1992, “Ahi Çelebi Camisi’nin Restorasyonu ve Çevre Düzenlemesi.” İTÜ Fen Bilimleri Enstitüsü Basılmamış Yüksek Lisans Tezi, İstanbul.

[24] Ahi Çelebi Cami. CourseHero. https://www.coursehero.com/file/45017105/Ahi-\%C3\%87elebiCamiidocx/ (22.09.2019 tarihinde erişilmiştir).

[25] Eyüpgiller, K., 2004, “Ahi Çelebi Camisi Restitüsyon ve Restorasyon Projeleri.” KTVKK Arşivi.

[26] Rabia, Ö., Ayten E., 2010, The Protection Problems and Reparations of Ahi Çelebi Mosque in Istanbul, Advanced Materials Researched Vols. 133-134 (2010) pp 1027-1032, Trans Tech Publications, Switzerland.

[27] Cezar, M., 1963, Osmanlı Devrinde Istanbul Yapılarında Tahribat Yapan Yangınlar ve Tabii Afetler, Türk Sanat Tarihi Araştırmaları ve İncelemeleri I, s 327-414, İstanbul

[28] Andreasyan, H . (2011). Eremya Çelebi'nin Yangınlar Tarihi. Turkish Journal of History, 0 (27) , 5984 . https://dergipark.org.tr/tr/pub/iutarih/issue/9600/119808

[29] Sefer N., Ahunbay Z., Eminönü’nin Haliç Kıyı Bölgesindeki Vakıf Kültür Mirası'nın 1929-2015 Arasında Geçirdiği Onarımlar ve Uğradığı Kayıplar, Restorasyon Dergisi, https://core.ac.uk/download/pdf/50614185.pdf (20.09.2019 tarihinde erişilmiştir).

[30]Yenişafak Gazetesi. Ahi Çelebi Camii'ni su bastı. $10 \quad 12 \quad 2010$. https://www.yenisafak.com/gundem/ahi-celebi-camiini-su-basti-291924 (20.09.2019 tarihinde erişilmişsir).

[31] Şahin, Volkan. İşte İstanbul'da yaz yağmurunun afete dönmesinin nedeni. Hürriyet Gazetesi. 1807 2017. http://www.hurriyet.com.tr/gundem/istanbulda-yagis-rekoru-eylul-ve-ekimde-olur-temmuzda-rekorgelirse-1962017-40523620 (17.08.2019 tarihinde erişilmiştir).

[32] İstanbul'da Tarihi Yağış! 1807 2017. https://www.havaforum.com/istanbulda-tarihi-yagis-18-072017-sel/ (20.09.2019 tarihinde erişilmiştir).

[33] DHA. Tarihi caminin bahçesini su bast1 28.02.2018. Hürriyet Gazetesi. $28 \quad 022018$. http://www.hurriyet.com.tr/tarihi-caminin-bahcesini-su-basti-40756399 (20.09.2019 tarihinde erişilmiştir).

[34] Tarihi caminin bahçesini su bast1. CNNTÜRK. 2802 2018. https://www.cnnturk.com/turkiye/tarihicaminin-bahcesini-su-basti (20.09.2019 tarihinde erişilmiştir).

[35] Uzun, Ümit, ve Harun Uyanık. Sular altında kalan tarihi cami ibadete kapand1. DHA. 18082019. https://www.dha.com.tr/istanbul/sular-altinda-kalan-tarihi-cami-ibadete-kapandi/haber-1703783 (20.09.2019 tarihinde erişilmiştir).

[36] Ahunbay, Z., 2015, Karamürsel'in Od Taşı ve Tarihi Yapılarda Kullanımı, Uluslarası Karamürsel Alp ve Kocaeli Tarihi Sempozumu-II, 3-4.5 04 2015, Kocaeli 